\title{
Simulasi Modifikasi Konfigurasi Jaringan Spindel Menjadi Loop Tertutup Untuk Meningkatkan Keandalan Sistem Distribusi Menggunakan Software ETAP
}

\author{
Eko Nio Rizki \\ PLN UPDL Pandaan \\ niorizki@gmail.com
}

\begin{abstract}
Distribution reliability networks rely on any factor such as material quality, maintenance, operational pattern, protection device, and also network configuration. In the spindle network, the level of network reliability is level 3 (SPLN 52-3, 1983: 5). To level up the network reliability from level 3 to level 5 (zero downtime) [2][3], we need to modify the protection system from overcurrent relay and ground fault relay to line differential relay in each distribution substation. Besides, the Load Break Switch in each customer cubicle substation and the connection substation should be replaced by a circuit breaker. Spindle network which operated open loop in the connection substation switch to normally close operated, so it can be called as a closed-loop network. This modification purpose is there is no downtime in case of ground fault or phase to phase short circuit on the network cable. Before this kind of modification and the setting is applied into the real network, we make a simulation using an application called ETAP and no mismatch trip from 7-time experiment consist of a ground fault and phase to phase short circuit in 7 cable.
\end{abstract}

Keywords: spindle, line differential relay, closed-loop, fault

\begin{abstract}
Abstrak
Keandalan jaringan distribusi tenaga listrik bergantung kepada beberapa faktor, di antaranya adalah kualitas material, pemeliharaan, pola operasi, peralatan proteksi yang digunakan dan juga konfigurasi jaringan. Pada Jaringan Spindel tingkat keandalan jaringan adalah level 3 (SPLN 523, 1983: 5), Untuk meningkatkan level keandalan dari level 3 menjadi level 5 (tanpa padam)[2], diperlukan perubahan sistem proteksi dan pola operasi dari jaringan spindel, yaitu dengan mengganti sistem proteksi yang semula menggunakan Overcurrent Relay dan Ground Fault Relay menjadi sisitem proteksi Line Differential Relay pada setiap gardu distribusinya, selain itu Load Break Switch yang terdapat pada masing masing kubikel pelanggan dan juga pada gardu hubung yang terdapat di ujung jaringan spindel diganti dengan circuit beraker. Jaringan spindel yang mulanya beroperasi normally open pada gardu hubung, dirubah pola operasinya menjadi normally close, maka dari itu jaringan ini disebut jaringan Loop tertutup. Dengan konfigurasi jaringan loop tertutup ini jika terjadi gangguan fasa - fasa ataupun fasa tanah pada kabel tidak akan berdampak terhadap pelanggan. Sebelum mengaplikasikan modifikasi dan setting proteksi ini ke jaringan yan sebenarnya, kami membuat simulasi pada software ETAP, dan tidak ditemukan kesalahan setting pada 7 kali percobaan ground fault dan hubung singkat fasa fasa pada 7 kabel yang ada pada jaringan.
\end{abstract}

Kata kunci: spindel, line differential relay, loop tertutup, gangguan 


\section{Energi dan Kelistrikan: Jurnal Ilmiah}

Vol. 13, No. 1, Januari - Juni 2021, P-ISSN 1979-0783, E-ISSN 2655-5042

https://doi.org/10.33322/energi.v13i1.1199

\section{PENDAHULUAN}

Keandalan distribusi energi listrik merupakan sesuatu yang sangat penting bagi PT PLN (Persero) dan juga bagi pelanggannya. Baik atau tidaknya keandalan jaringan PLN akan berdampak pada pendapatan dan juga citra PLN di mata pelanggan. Untuk mencapai keandalan yang tinggi kita harus mempersiapkan mulai dari material yang digunakan pada jaringan dengan kualitas terbaik, sistem konfigurasi di jaringan juga harus disesuaikan dengan kebutuhan pelanggan, sistem proteksi yang cepat, sensitif, dan selektif [1], dan juga keterampilan personel dalam mengoperasikan dan memeliharan jaringan tersebut.

Rekonfigurasi jaringan dan merubah rancangan sistem proteksi dapat meningkatkan keandalan sistem distribusi. Yaitu dengan merubah sistem jaringan distribusi Spindel menjadi close loop dan sistem proteksi Over Current Relay dan Ground Fault Relay menjadi sistem proteksi line differntial relay. Kombinasi konfigurasi jaringan close loop dan line differential ini diharapkan dapat menjadi solusi untuk mencapai keandalan jaringan dengan tidak adanya pelanggan yang terdampak akibat gangguan.

Pada jurnal ini rekonfigurasi jaringan dilakukan melalui simulasi di aplikasi ETAP.

\section{DASAR TEORI}

\subsection{Jaringan Spindel}

Jaringan Spindel merupakan salah satu konfigurasi jaringan distribusi yang paling andal, jaringan spindel umumnya menggunakan Saluran Kabel Tanah Tegangan Menengah (SKTM), jaringan spindel sendiri terdiri dari beberapa penyulang yang terhubung dengan gardu hubung diujung jaringannya melalui peralatan yang kita sebut Load Break Switch dan terdapat 1 expres feeder yang pada saat normal (tidak ada gangguan) express feeder tidak boleh dibebani. [4]

\subsection{Differential Relay}

Relay differential adalah relay yang bekerja berdasarkan kesimbangan, yaitu membandingkan arus sekunder CT (current transfomer) yang terdapat pada terminal-terminal peralatan yang diamankan [5]. Relay differential bisa digunakan sebagai pengaman gangguan arus hubung singkat fasa dengan fasa (overcurrent) dan fasa dengan tanah (ground fault). Rele ini sangat selektif dan system kerjanya sangat cepat. Prinsip kerja Relay differental yaitu membandingkan arus yang mengalir melalui peralatan listrik yang diamankan (Kabel) menggunakan 2 CT, jika arus dalam CT 1 dan CT 2 sama besar maka Relay differential tidak bekerja. Dan apabila terjadi perbedaan arus di kedua CT maka Relay differential akan bekerja[6]. Hal ini memungkinkan relay differntial hanya akan bekerja jika ada gangguan di dalam zona proteksinya sebaliknya, relay differensial tidak akan bekerja jika gangguan berada di luar zona proteksinya, zona proteksi yang dimaksud adalah zona yang berada di antara $2 \mathrm{CT}$. [7]

\subsection{Transformator Arus}

Transformator arus atau current transformer adalah alat yang berfungsi untuk mengukur arus pada sisi Tegangan Menengah atau Tegangan Tinggi yang mempunyai besaran arus yang besar, yang kemudian ditransformasikan menjadi besaran arus yang lebih kecil dengan tingkat akurasi tinggi untuk kebutuhan proteksi dan pengukuran[8]. Untuk arus pengenal sisi primer CT dipilih sesuai dengan besarnya daya terpasang, secara umum rating arus sekunder CT yang digunakan oleh PLN adalah 1 Ampere dan 5 Ampere. Transformator Arus mempunyai persamaan sebagai berikut: 


$$
I_{1} * N_{1}=I_{2} N_{2}
$$

Dimana: $I_{1}=$ Arus Sisi Primer

$\mathrm{I}_{2}=$ Arus Sisi Sekunder

$\mathrm{N}_{1}=$ Jumlah belitan sisi primer

$\mathrm{N}_{2}=$ Jumlah belitan sisi sekunder

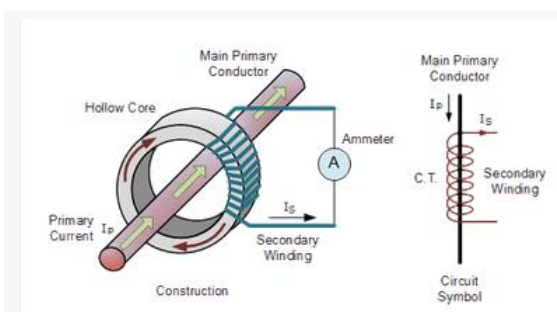

Gambar 1. Transformator arus atau Current Transformer

\subsection{Circuit Breaker}

Circuit Breaker (CB) atau Pemutus Tenaga (PMT) adalah peralatan mekanis yang mampu menghubungkan dan memutus arus beban pada kondisi normal dan juga menghubungkan dan memutus arus beban pada saat terjadi gangguan hubung singkat baik itu hubung singkat fasa - fasa ataupun fasa - tanah sesuai dengan ratingnya. Pengoperasian CB / PMT bisa dilakukan pada saat kondisi berbeban maupun tidak berbeban [9].

\section{PEMBAHASAN}

\subsection{Perubahan Jaringan dari Spindel ke Close Loop}

Pada jaringan Loop tertutup, konfigurasi jaringan yang digunakan adalah Jaringan Spindel dengan melakukan beberapa perubahan, di antaranya merubah peralatan proteksi yang semula menggunakan Overcurrent dan Ground Fault relay menjadi line Differential Relay[14], yang posisinya diletakkan pada kubikel pelanggan sisi incoming dan outgoing. Karena pada kubikel pelanggan telah dipasang relay differential pada sisi incoming dan outgoing, maka Load Break Switch LBS [10] pada sisi Incoming dan Outgoing harus diganti juga dengan Circuit Breaker (CB), seperti pada gambar berikut:

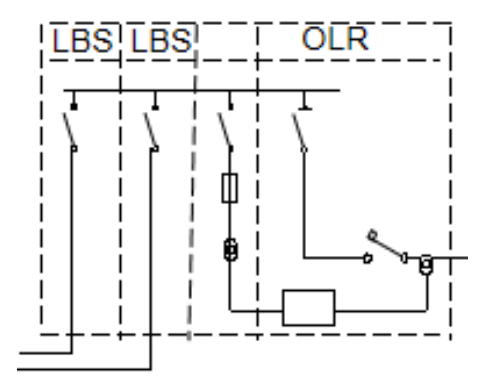

Gambar 2. Kubikel Pelanggan Pada Konfigurasi Spindel

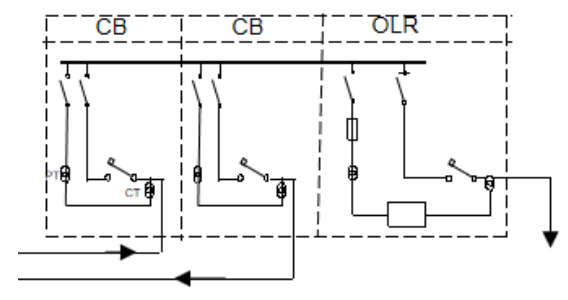

Gambar 3. Kubikel Pelanggan Pada Konfigurasi Spindel

Perubahan berikutnya adalah pada gardu hubung jaringan spindel yang semula menggunakan LBS dengan posisi LBS terbuka saat kondisi normal, pada sistem loop tertutup LBS digantikan 


\section{Energi dan Kelistrikan: Jurnal Ilmiah}

Vol. 13, No. 1, Januari - Juni 2021, P-ISSN 1979-0783, E-ISSN 2655-5042

https://doi.org/10.33322/energi.v13i1.1199

dengan Circuit breaker yang dilengkapi dengan line differential relay, dan posisi CB dalam kondisi normal yaitu tertutup. Single line dari jaringan loop terutup adalah sebagai berikut:
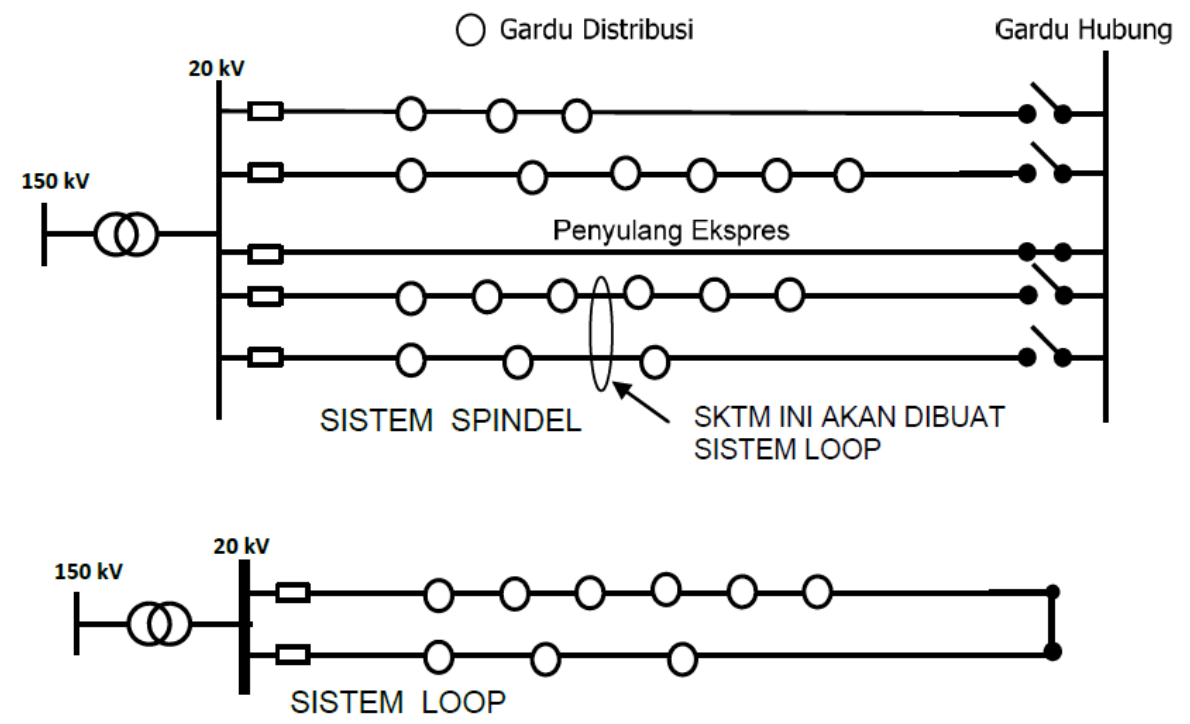

Gambar 4. Single Line Konfigurasi Spindel yang drubah menjadi Loop Tertutup

\subsection{Membuat Desain Jaringan Menggunakan Software ETAP}

Pada pembuatan desain jaringan ini kami memasukkan total 5 beban pelanggan pada 2 penyulang, 3 beban di penyulang sebelah kiri, 2 beban di kanan. Setiap beban dibuat 1 seksi, yang mana diapit oleh seperangkat sistem proteksi differensial, sehingga jika terdapat gangguan di salah 1 kabel, maka beban masih dapat dilayani oleh kabel lainnya melalui penyulang lain, karena pada dasarnya konfigurasi jaringan yang digunakan adalah spindel dengan CB tertutup di gardu hubung yang tidak memerlukan waktu dalam melakukan manuver jaringan. Berbeda dengan jaringan spindel yang masih ada jeda waktu beberapa saat untuk melakukan manuver jaringan yang terkena gangguan [11]. Dalam mendesain suatu jaringan loop tertutup di ETAP, polaritas CT harus diperhatikan agar proteksi differential di dalam jaringan tersebut berfungsi dengan baik, Output dari relay harus diisi sesuai dengan CB yang akan dikendalikan oleh relay tersebut, menonaktifkan jenis relay yang tidak digunakan, semisal kita memilih relay yang mempunyai 3 fungsi, yaitu OCR, GFR, dan Relay Differential, karena yang kita gunakan adalah Relay Differential, maka OCR dan GFR harus dinonaktifkan, semua hal tersebut dilakukan untuk meNjamin simulasi jaringan yang kita buat berjalan sesuai keinginan kita [12].

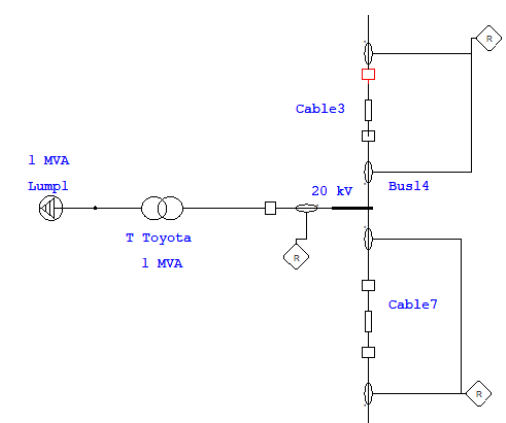

Gambar 5. Beban (pelanggan) yang di apit oleh sistem proteksi relay differential 
Untuk desain secara keseluruhan jaringan loop tertutup adalah sebagai berikut:

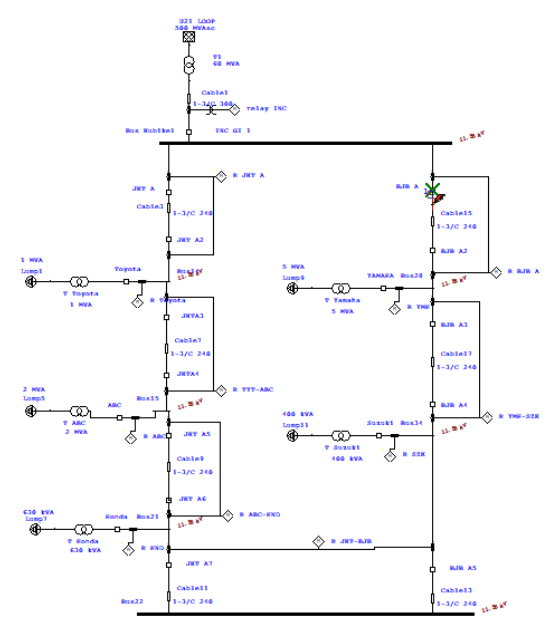

Gambar 6. Desain jaringan loop tertutup secara keseluruhan

\subsection{Hasil Simulasi}

Simulasi kali ini menggunakan fitur star protective device coordination, dengan meletakkan gangguan pada 7 kabel dan 6 busbar kubikel yang ada di jaringan, masing masing kabel dan busbar kubikel diberikan gangguan fasa - fasa dan fasa -tanah. Berikut adalah hasil pengujiannya:

Tabel 1. Hasil simulasi

*Ket: $\sqrt{ }=$ Relay dan CB yang trip sesuai (Sistem proteksi berjalan baik)

\begin{tabular}{|c|c|c|c|}
\hline \multirow{2}{*}{ No } & \multirow{2}{*}{ Letak Gangguan } & \multicolumn{2}{|c|}{ Hasil Simulasi Jenis Gangguan* } \\
\hline & & Fasa - Fasa & Fasa - Tanah \\
\hline 1 & Cable 3 & $\sqrt{ }$ & $\sqrt{ }$ \\
\hline 2 & Cable 7 & $\sqrt{ }$ & $\sqrt{ }$ \\
\hline 3 & Cable 9 & $\sqrt{ }$ & $\sqrt{ }$ \\
\hline 4 & Cable 11 & $\sqrt{ }$ & $\sqrt{ }$ \\
\hline 5 & Cable 13 & $\sqrt{ }$ & $\sqrt{ }$ \\
\hline 6 & Cable 15 & $\sqrt{ }$ & $\sqrt{ }$ \\
\hline 7 & Cable 17 & $\sqrt{ }$ & $\sqrt{ }$ \\
\hline 8 & Bus 14 & $x$ & $x$ \\
\hline 9 & Bus 15 & $x$ & $x$ \\
\hline 10 & Bus 21 & $x$ & $x$ \\
\hline 11 & Bus 22 & $\sqrt{ }$ & $\sqrt{ }$ \\
\hline 12 & Bus 28 & $x$ & $x$ \\
\hline 13 & Bus 34 & $x$ & $x$ \\
\hline
\end{tabular}

Dari hasil simulasi tersebut dapat dilihat bahwa seluruh gangguan yang ada pada kabel dapat diatasi dengan baik oleh sistem proteksi yang sudah didesain. Tetapi gangguan pada busbar tidak dapat diatasi (kecuali busbar 22 gardu hubung). Hal ini disebabkan gangguan pada bus tidak termasuk pada zona proteksi relay differensial dikarenakan posisi gangguan berada diluar $2 \mathrm{CT}$ yang berpasangan yang berfungsi pembanding arus, sehingga gangguan tidak dapat terdeteksi [13]. 


\section{Energi dan Kelistrikan: Jurnal Ilmiah}

Vol. 13, No. 1, Januari - Juni 2021, P-ISSN 1979-0783, E-ISSN 2655-5042

https://doi.org/10.33322/energi.v13i1.1199

\section{KESIMPULAN DAN SARAN}

Dari hasil simulasi sistem proteksi konfigurasi loop tertutup dengan menggunakan differensial relay ini bisa menjadi solusi untuk mengatasi keandalan jaringan terutama di daerah padat seperti pusat bisnis, pusat perkantoran pemerintah atau swasta, industri dsb, karena dengan sistem ini ketika jaringan mengalami gangguan, pelanggan tidak mengalami padam karena jaringan ini sudah dilengkapi dengan jalur penyedian listrik 2 arah. Kelemahan sistem ini adalah membutuhkan banyak peralatan proteksi seperti CB, CT, dan Relay sehingga diperlukan investasi yang tinggi juga, selain itu sistem ini sangat bergantung pada sistem telekomunikasi, karena untuk memerintahkan CB yang letaknya jauh, relay membutuhkan media untuk mentransfer data, dalam hal ini bisa menggunakan fiber optic, internet nirkabel (modem 3G/4GR), jika sistem komunikasi tersebut gagal bekerja atau mengalami gangguan, maka sistem proteksi juga tidak akan bisa berfungsi.

\section{DAFTAR PUSTAKA}

[1] Pandjaitan, B. (2012). Praktik-Praktik Proteksi Sistem Tenaga Listrik. Andi Offset.

[2] Perdana, W. P., Nur Hasanah, R., \& S. Dachlan, H. (2009). Evaluasi Keandalan Sistem Tenaga Listrik Pada Jaringan Distribusi Primer Tipe Radial Gardu Induk Blimbing. Jurnal EECCIS.

[3] Nono, Moelyono. 1999. Pengantar Sistem Distribusi Tenaga Listrik. Surabaya: Jurusan Teknik Elektro Fakultas Teknologi Industri, ITS.

[4] Sarimun, W., \& Prima Aridani, R. (2017). Proteksi Differential Relay Pada Sistem Distribusi Tenaga Listrik. PT PLN (Persero) Pusat Pendidikan dan Pelatihan.

[5] Subianto. (2016). Studi Sistem Proteksi Rele Diferensial Pada Transformator PT PLN (Persero) Keramasan. Jurnal Surya $\quad$ Energy, 1. https://doi.org/https://doi.org/10.32502/jse.v1i1.564

[6] S. G. A. Perez, M. S. Sachdev and T. S. Sidhu, "Modeling relays for use in power system protection studies," Canadian Conference on Electrical and Computer Engineering, 2005., Saskatoon, Sask., 2005, pp. 566-569, doi: 10.1109/CCECE.2005.1556994.

[7] Syukriyadin, Syahrizal, \& Rizky Nakhrisya, C. (2011). Analisis Proteksi Relay Differensial Terhadap Gangguan Internal dan Ekternal Transformator Menggunakan PSCAD/EMTDC. Jurnal Rekayasa Elektrika, 9. https://doi.org/10.17529/jre.v9i3.158

[8] Tambunan, J. (2019). PENGUJIAN RUTIN TRAFO ARUS 24 KV DI LABORATORIUM HUBUNG SINGKAT PT. PLN (PERSERO) PUSLITBANG KETENAGALISTRIKAN. JURNAL ILMIAH SUTET, 8(1), 34 - 43. https://doi.org/10.33322/sutet.v8i1.714

[9] Rahmi Wahyuni Kamal, A., Mustabsyirah Dahlan, S., Bakhtiar, \& Indrawan Wawan, A. (2016). Analisis Gangguan Hubung Singkat Satu Fasa ke Tanah Terhadap PMT di Penyulang Takalar20 KV GI Sungguminasa. Politeknik Negeri Ujung Pandang.

[10] E. Jonsson, N. S. Aanensen and M. Runde, "Current Interruption in Air for a Medium-Voltage Load Break Switch," in IEEE Transactions on Power Delivery, vol. 29, no. 2, pp. 870-875, April 2014, doi: 10.1109/TPWRD.2013.2280300.

[11] Simanjuntak, R.P.M., Syafriyudin, S., and Firman, B. (2017). ANALISIS KEANDALAN PENEMPATAN RECLOSER DAN BESAR ARUS HUBUNG SINGKAT DI PT. PLN (PERSERO) DISTRIBUSI AREA YOGYAKARTA. Jurnal Elektrikal.

[12] Kamel, A., Alaam, M. A., Azmy, A. M., \& Abdelaziz, A. Y. (2013). Protection Coordination of Distribution Systems Equipped with Distributed Generations. Electrical and Electronics Engineering: An International Journal, 2(2), 1-13

[13] Dewadasa, M., Ghosh, A., \& Ledwich, G. (2011). Protection of microgrids using differential relays. In 2011 21st Australasian Universities Power Engineering Conference, AUPEC 201 


\section{Energi dan Kelistrikan: Jurnal Ilmiah}

Vol. 13, No. 1, Januari - Juni 2021, P-ISSN 1979-0783, E-ISSN 2655-5042 https://doi.org/10.33322/energi.v13i1.1199

[14] Haron, A. R., Mohamed, A., \& Shareef, H. (2013). Coordination of Overcurrent, Directional and Differential Relays for the Protection of Microgrid System. Procedia Technology, 11, 366-373. https://doi.org/10.1016/j.protcy.2013.12.204

[15] Hall, I., Beaumont, P. G., Baber, G. P., Shuto, I., Saga, M., Okuno, K., \& Ito, H. (2003). New line current differential relay using GPS synchronization. In 2003 IEEE Bologna PowerTech - Conference Proceedings (Vol. 3, pp. 670-677). https://doi.org/10.1109/PTC.2003.1304464. 